OPEN ACCESS

Edited by:

Arash Zibaee,

University of Gilan, Iran

Reviewed by:

Muthugounder S. Shivakumar,

Periyar University, India

Gustavo Bueno Rivas,

Oswaldo Cruz Foundation, Brazi

*Correspondence:

Xuguo Zhou

xuguozhou@uky.edu

Qingjun Wu

wuqingjun@caas.cn

Specialty section:

This article was submitted to

Invertebrate Physiology,

a section of the journal

Frontiers in Physiology

Received: 12 January 2017 Accepted: 20 February 2017

Published: 13 March 2017

Citation:

Yuan G, Wan Y, Li X, He B, Zhang Y, $X u B$, Wang $S$, Xie W, Zhou $X$ and

Wu Q (2017) Development of

Near-Isogenic Lines in a

Parthenogenetically Reproduced

Thrips Species, Frankliniella

occidentalis. Front. Physiol. 8:130.

doi: 10.3389/fphys.2017.00130

\section{Development of Near-Isogenic Lines in a Parthenogenetically Reproduced Thrips Species, Frankliniella occidentalis}

\author{
Guangdi Yuan ${ }^{1}$, Yanran Wan ${ }^{1}$, Xiaoyu $\mathrm{Li}^{1}$, Bingqing He ${ }^{1}$, Youjun Zhang ${ }^{1}$, Baoyun $\mathrm{Xu}{ }^{1}$, \\ Shaoli Wang ${ }^{1}$, Wen Xie ${ }^{1}$, Xuguo Zhou ${ }^{2 *}$ and Qingjun Wu ${ }^{1 *}$ \\ ${ }^{1}$ Institute of Vegetables and Flowers, Chinese Academy of Agricultural Sciences, Beijing, China, ${ }^{2}$ Department of Entomology, \\ University of Kentucky, Lexington, KY, USA
}

Although near-isogenic lines (NILs) can standardize genetic backgrounds among individuals, it has never been applied in parthenogenetically reproduced animals. Here, through multiple rounds of backcrossing and spinosad screening, we generated spinosad resistant NILs in the western flower thrips, Frankliniella occidentalis (Pergande) (Thysanoptera: Thripidae), with a haplo-diploid reproduction system. The resultant $F$. occidentalis NIL-R strain maintained a resistance ratio over 30,000-fold, which was comparable to its parental resistant strain, Spin-R. More importantly, F. occidentalis NIL-R shared $98.90 \%$ genetic similarity with its susceptible parental strain Ivf03. By developing this toolset, we are able to segregate individual resistance and facilitate the mechanistic study of insecticide resistances in phloem-feeding arthropods, a group of devastating pest species reproducing sexually as well as asexually.

Keywords: Frankliniella occidentalis, near-isogenic lines, insecticide resistance, spinosad, ISSR

\section{INTRODUCTION}

Near-isogenic lines (NILs) are strains which genetic makeups are identical except for few specific locations or genetic loci (Muehlbauer et al., 1988; Young et al., 1988). The use of NILs minimizes the effects caused by different genetic backgrounds to avoid epistatic gene interactions that may occur in outbred strains (Zhu et al., 2015). NILs have been extensively used in gene mapping, gene function analysis, and the development of new cultivars in plants (Brouwer and St Clair, 2004; von-Korff et al., 2004; Edwards et al., 2005; Loudet et al., 2005; Blanco et al., 2006).In insects, NILs are used predominantly in the context of insecticide or stress resistance, including the inheritance of resistance (Roush and Wolfenbarger, 1985; White and Bell, 1988), relative fitness between resistant and susceptible populations (Jiang et al., 2007), discovery of molecular markers (Mu et al., 2005a), and identification of resistance genes (Hardstone et al., 2010). Classic NILs construction methods, such as backcross inbred lines (BILs) and recombinant inbred lines (RILs), are applicable exclusively to amphigenetic insects, including fruit fly, beet armyworm, diamondback moth, and silkworm (Pierce and Lucchesi, 1981; Mu et al., 2004; Yuan et al., 2010; Zhu et al., 2015). Social animals, such as honeybees, ants, and termites (Tucker, 1958; Bell, 1982; Matsuura, 2010), and phloem-sucking arthropods, including aphids, thrips, whiteflies, and spider mites (Helle and Bolland, 1967; Dixon, 1987; Bink-Moenen and Mound, 1990; Murai, 1990), reproduce both sexually and asexually. Therefore, a novel construction method is needed to establish NILs in these animals. 
The western flower thrips, Frankliniella occidentalis (Pergande) (Thysanoptera: Thripidae), has a haplo-diploid reproduction system, in which females and males are developed from fertilized and unfertilized eggs, respectively. Their unmated females produce only male offspring, whereas mated females produce both males and females (Bryan and Smith, 1956). As a polyphagous insect, $F$. occidentalis causes extensive damages to a wide range of crops by feeding, egg laying, and vectoring of plant tospoviruses (Sakimura, 1962). Its small body size, high fecundity, and short life cycle facilitate $F$. occidentalis to develop resistance to wide range of pesticides, including organochlorines, organophosphates, carbamates, pyrethroids, and spinosad (Immaraju et al., 1992; Brødsgaard, 1994; Martin et al., 1994; Robb et al., 1995; Zhao et al., 1995; Bielza et al., 2007b). Although spinosad has been the most effective synthetic pesticide against F. occidentalis (Thompson et al., 2000; Williams et al., 2003), cases of spinosad resistance and management failure have been reported globally (Loughner et al., 2005; Bielza et al., 2007b; Herron and James, 2007). In China, F. occidentalis has developed over 100-fold resistance to spinosad in the field, and caused damages to regional agriculture (Wan et al., 2016).

A genetic linkage experiment has demonstrated that spinosad resistance in F. occidentalis was controlled by a single autosomal recessive gene and was not influenced by maternal effects (Bielza et al., 2007a). To study this recessive trait, the establishment of a spinosad resistant NIL sharing the same genetic background with susceptible $F$. occidentalis is critical for the mechanistic and genetic understanding of spinosad resistance. During the development of NILs, a series of molecular markers were used in marker-assisted selection (MAS) or examining the genetic background of backcross derivatives, like restriction fragment length polymorphism (RFLP) (Shen et al., 2001), Simple Sequence Repeat (SSR) (Wang et al., 2009) and inter-simple sequence repeat (ISSR) (Zhu et al., 2015). Because of a higher frequency of polymorphism, a greater repeatability and a lower cost, ISSR was chosen for this study (Godwin et al., 1997). Amplification of ISSR-PCR, however, is affected by the concentration of each PCR ingredient, and different combinations. Therefore, an orthogonal experiment was designed to optimize the ISSR-PCR reaction system in $F$. occidentalis to obtain as many polymorphic bands as possible to achieve an accurate measurement of near-isogenicity.

\section{MATERIALS AND METHODS}

\section{Frankliniella Occidentalis Strains}

One spinosad-susceptible (Ivf03) and one spinosad-resistant strain (Spin-R) of F. occidentalis were used. The susceptible Ivf03 strain was collected in a greenhouse at the Institute of Vegetables and Flowers, Chinese Academy of Agricultural Sciences (CAAS) in Beijing, China in 2003, and was subsequently maintained on bean pods without exposure to any insecticides (Zhang et al., 2007). The resistant Spin-R strain was derived from Ivf03 by exposing thrips to bean pods treated with formulated spinosad (Spinoace, Dow AgroSciences China Co., Ltd., China), and the resistance ratio of Spin-R was over $>10^{4}$-fold (Hou et al., 2013).
Both strains were kept separately but under the same conditions, i.e., $27 \pm 1^{\circ} \mathrm{C}$ and $50 \%$ relative humidity.

\section{Toxicity Bioassay}

A leaf-tube residual film method (Hou et al., 2014) was adopted to determine the diagnostic concentration between Ivf03 and Spin$\mathrm{R}$ strains, and to calculate the resistance ratios of the offspring. At least five concentrations were used in each bioassay with four replicates for each concentration and 15 adult females for each replication. The treated thrips were maintained at $28^{\circ} \mathrm{C}$ with a photoperiod of LD 16:8. Mortality was recorded after $48 \mathrm{~h}$. Poloplus program was used to analyze the dose-response data (POLO-PC, LeOra Software, 1997). Resistance ratios were calculated by dividing $\mathrm{LC}_{50}$ values for each strain by that of the Ivf03 strain. If the $95 \%$ fiducial limits did not overlap, the spinosad resistance levels of these two strains were considered significantly different (St Leger et al., 1996).

\section{Construction of Nils in $F$. occidentalis}

Per our ongoing research, F. occidentalis female can produce approximately 200 offsprings over the course of its lifetime (QJW, unpublished). For the following experiments, we selected over 500 pupae in each round of crosses. After eclosion, we removed

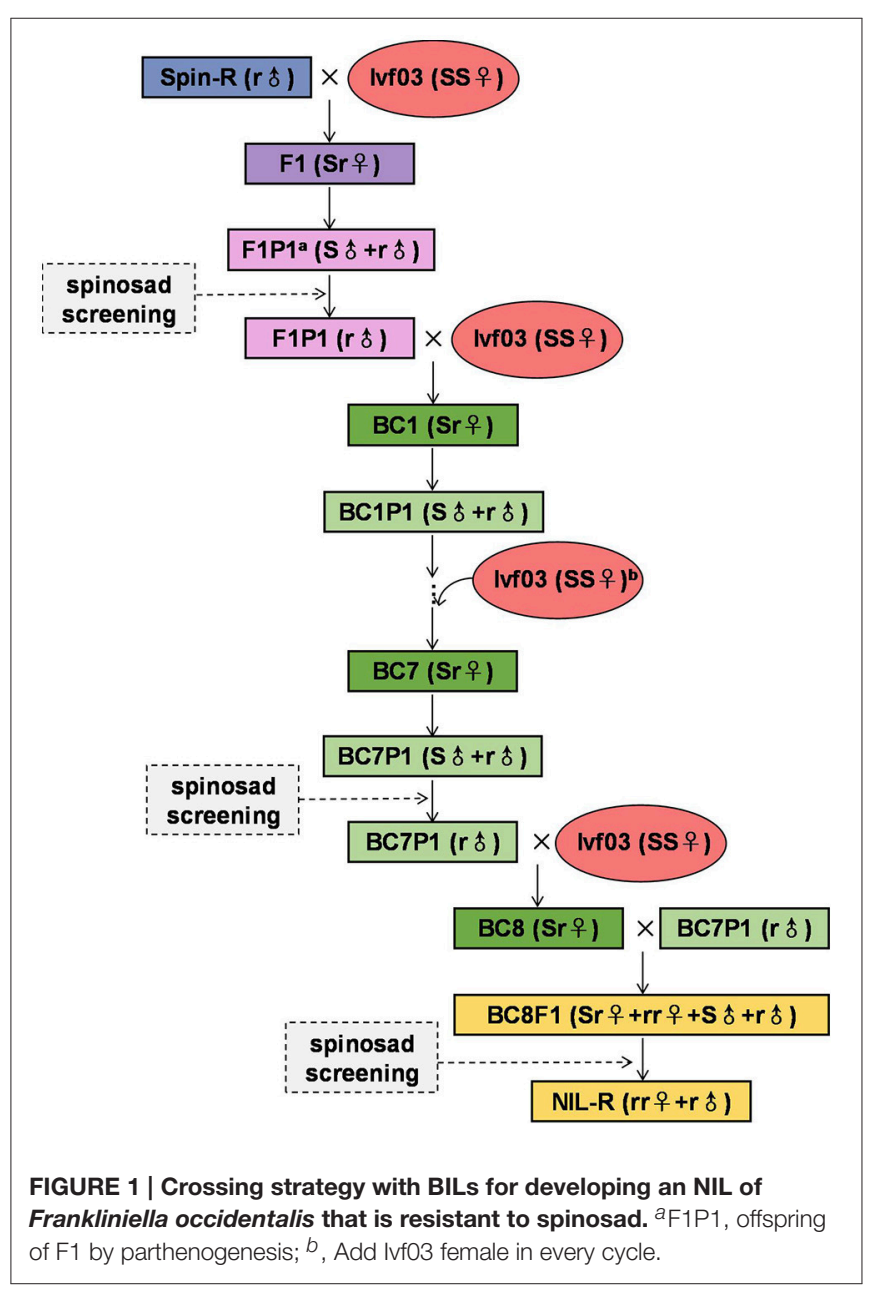


dead pupae and males, and the remaining females ( $>200)$ were collected for the parthenogenetic reproduction, which, in theory, would produce over 40,000 individuals. A fine brush pen was used to transfer Ivf03 pupae to $2 \mathrm{~mL}$ microcentrifuge tubes (one pupa per tube). After eclosion, females (SSor) were collected in a glass jar in which they were crossed with Spin-R adult males (ro). Approximately 100-300 individuals from each sex were used in each backcrosses, and the ratio of male and female was 1:1 (at least 100 pairs of susceptible females and resistant males were mass crossed). Offspring (F1, Sro $\left.+\mathrm{So}^{x}\right)$ were maintained on fresh bean pods until the pupal stage. Pupae from the $\mathrm{F} 1$ generation were placed in $2 \mathrm{~mL}$ microcentrifuge tubes (one pupa per tube). After eclosion, those F1 virgin females parthenogenetically reproduced their offspring $\left(\mathrm{F} 1 \mathrm{P} 1, \mathrm{~S} \sigma^{x}+\mathrm{ro}^{x}\right)$. The resultant offsprings were treated with $50 \mathrm{mg} / \mathrm{L}$ spinosad, a diagnostic concentration that killed all susceptible males but had no impact on resistant males. The survivors $\left(\mathrm{r}^{7}\right)$ were then backcrossed with Ivf03 females to obtain the BC1 generation $\left(\operatorname{Sr}++\mathrm{So}^{x}\right)$. This process was repeated for eight cycles to the BC8 generation. Virgin females (Sro) from BC8 were then backcrossed with the father generation (BC7P1, ro $\sigma^{x}$ ) to obtain $\mathrm{BC} 8 \mathrm{~F} 1\left(\right.$ Sro + rro $\left.+\mathrm{So} \sigma^{7}+\mathrm{ro}^{7}\right)$. BC8F1 were screened with $50 \mathrm{mg} / \mathrm{L}$ spinosad to finally obtain the spinosad-resistant NIL-R strain $\left(\right.$ rro $\left.+\mathrm{ro}^{\top}\right)$ (Figure 1).

\section{DNA Extraction}

Adults from the two parental strains, the five backcrossed offsprings, and the NIL-R strain were collected and stored individually in a $1.5 \mathrm{~mL}$ centrifuge tube at $-80^{\circ} \mathrm{C}$. Total genomic DNA was extracted using the TIANamp micro DNA kit (TIANGEN Biotech Co., Ltd., Beijing, China) following the manufacturer's protocol. gDNA was extracted from five adult females in each strain, and the concentration ranged between 30 and $50 \mathrm{ng} / \mu \mathrm{L}$, which was estimated by NanoDrop 2000c spectrophotometer (Thermo Fisher Scientific Inc., Waltham, MA, USA).

\section{Optimization of ISSR-PCR Reaction System}

Primer sets that amplified the most polymorphic bands, UBC842, was chosen for ISSR-PCR. Furthermore, an orthogonal experiment was designed to optimize ISSR-PCR, including concentrations for $\mathrm{Mg}^{2+}$, Taq DNA polymerase (CoWin Biosciences, Beijing, China), dNTPs, DNA templates, and primers (Table 1). Each PCR reaction system had a total volume of $20.0 \mu \mathrm{L}$ that included $2.0 \mu \mathrm{L}$ of $10 \mathrm{x}$ PCR buffer $\left(\mathrm{Mg}^{2+}\right.$ free) (TaKaRa, Dalian, China). Quantity of each ingredient was determined based on the concentration of the stock solution, and distilled water was added to complete the total volume. PCR products were detected by electrophoresis (Figure 2) and were scored using an orthogonal design-direct analysis based on the quantity and brightness of the gel bands. The experiment was conducted and scored three times. IBM SPSS Statistics Version 19 software (SPSS Inc., Chicago, IL) was used for variance analysis. To search for the optimal concentration of individual factors, mean values (Table 2) were plotted against factor levels. Levels with the highest values represented the optimal concentrations of individual factors (Figure 2).

\section{Evaluation of the Near-Isogenicity by ISSR Markers}

ISSR analysis was used for the genomic evaluation of the two parental strains, the eight backcross strains, and the final NIL-R strain. Primers (Table 3) that resulted in polymorphic amplifications in F. occidentalis were screened from the UBC Primer Set \#9 (University of British Columbia Nucleic AcidProtein Service Unit, UBC Primer Set \#9-NAPS Unit). ISSRPCR was carried out in a thermal cycler (S1000, AB) using a regime of $94^{\circ} \mathrm{C}$ for $4 \mathrm{~min}$; followed by 35 cycles of $94^{\circ} \mathrm{C}$ for $40 \mathrm{~s}, 50-59^{\circ} \mathrm{C}$ for $40 \mathrm{~s}$, and $72^{\circ} \mathrm{C}$ for $80 \mathrm{~s}$; and a final extension of $72^{\circ} \mathrm{C}$ for $10 \mathrm{~min}$. Clear and reproducible amplicon

TABLE 1 | $\mathrm{L}_{16}\left(4^{5}\right)$ orthogonal array for optimization of ISSR-PCR.

\begin{tabular}{|c|c|c|c|c|c|c|c|c|}
\hline Factor treatment & $\mathrm{Mg}^{2+}\left(\mathrm{mmol} \cdot \mathrm{L}^{-1}\right)$ & dNTPs (mmol. $\left.\mathrm{L}^{-1}\right)$ & Primer $\left(\mu \mathrm{mol} \cdot \mathrm{L}^{-1}\right)$ & Taq polymerase (U) & DNA (ng) & & Scores & \\
\hline 1 & 1.0 & 0.10 & 1.0 & 0.5 & 10 & 7 & 8 & 8 \\
\hline 2 & 1.0 & 0.15 & 2.0 & 1.0 & 20 & 15 & 13 & 15 \\
\hline 3 & 1.0 & 0.20 & 3.0 & 1.5 & 30 & 16 & 14 & 14 \\
\hline 4 & 1.0 & 0.25 & 4.0 & 2.0 & 40 & 12 & 13 & 11 \\
\hline 5 & 2.0 & 0.10 & 2.0 & 1.5 & 40 & 11 & 11 & 14 \\
\hline 6 & 2.0 & 0.15 & 1.0 & 2.0 & 30 & 5 & 6 & 7 \\
\hline 7 & 2.0 & 0.20 & 4.0 & 0.5 & 20 & 12 & 14 & 12 \\
\hline 8 & 2.0 & 0.25 & 3.0 & 1.0 & 10 & 11 & 11 & 13 \\
\hline 9 & 3.0 & 0.10 & 3.0 & 2.0 & 20 & 7 & 6 & 6 \\
\hline 10 & 3.0 & 0.15 & 4.0 & 1.5 & 10 & 8 & 8 & 9 \\
\hline 11 & 3.0 & 0.20 & 1.0 & 1.0 & 40 & 12 & 13 & 11 \\
\hline 12 & 3.0 & 0.25 & 2.0 & 0.5 & 30 & 21 & 23 & 22 \\
\hline 13 & 4.0 & 0.10 & 4.0 & 1.0 & 30 & 9 & 9 & 10 \\
\hline 14 & 4.0 & 0.15 & 3.0 & 0.5 & 40 & 9 & 9 & 8 \\
\hline 15 & 4.0 & 0.20 & 2 & 2.0 & 10 & 8 & 9 & 7 \\
\hline 16 & 4.0 & 0.25 & 1 & 1.5 & 20 & 10 & 11 & 9 \\
\hline
\end{tabular}



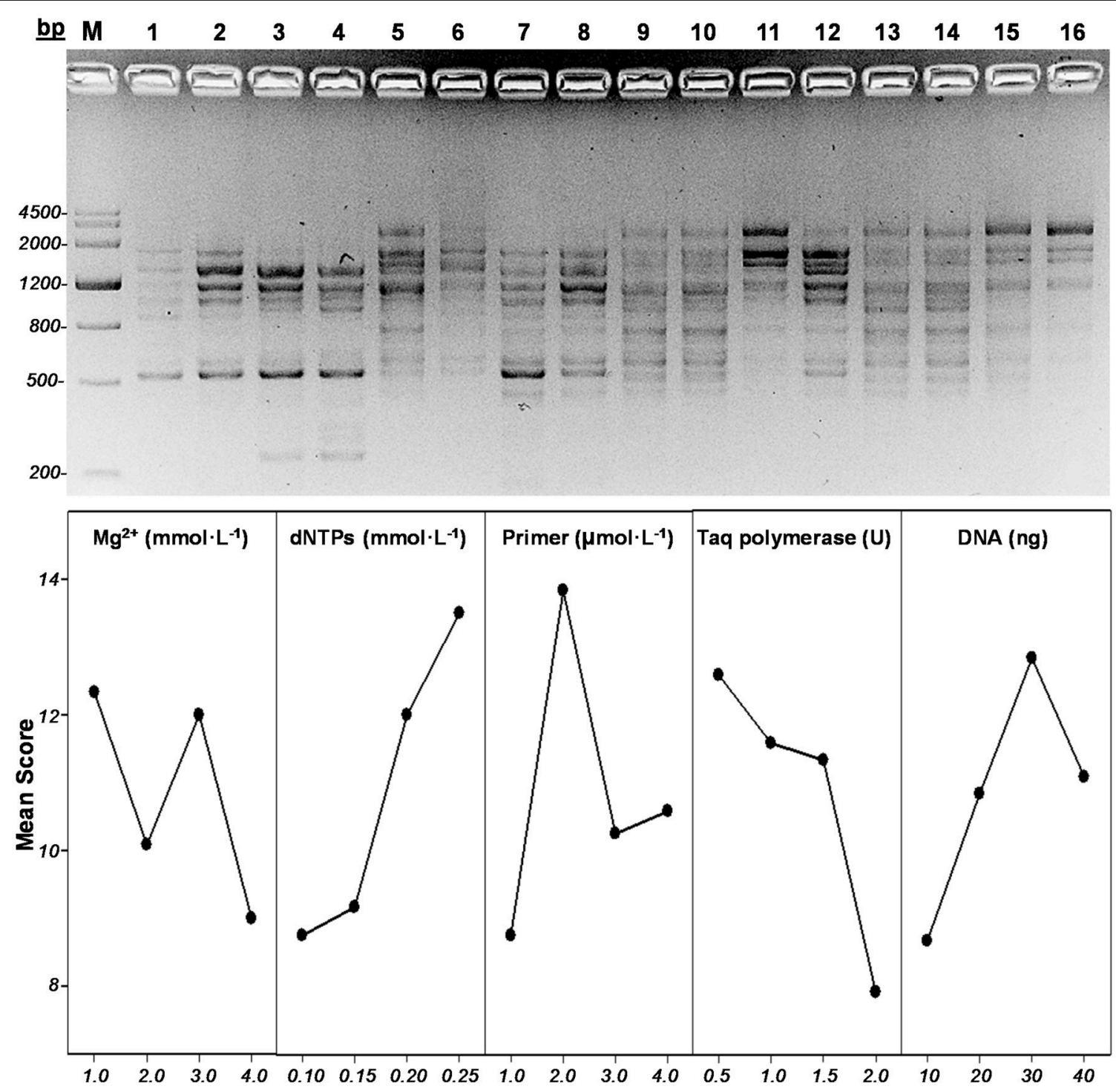

FIGURE 2 | ISSR analysis. (A) Electrophoretic profiles of $F$. occidentalis orthogonal ISSR-PCR. Lane 1-16 are the treatments, which involved four levels of the following factors: $\mathrm{Mg}^{2+}$ concentration, Taq DNA polymerase content, dNTP concentration, DNA content, and primer concentration. M: Marker III (TIANGEN). (B) Scores of five factors plotted against factor level.

TABLE 2 | Variance analysis of individual factors affecting ISSR-PCR.

\begin{tabular}{|c|c|c|c|c|c|}
\hline Level & $\mathrm{Mg}^{2+}\left(\mathrm{mmol} \cdot \mathrm{L}^{-1}\right)$ & dNTPs (mmol. $\left.\mathrm{L}^{-1}\right)$ & Primer $\left(\mu \mathrm{mol} \cdot \mathrm{L}^{-1}\right)$ & Taq polymerase (U) & DNA (U) \\
\hline Level 1 & $12.333 a$ & $8.750 a$ & $8.750 \mathrm{a}$ & $12.583 a$ & $8.667 a$ \\
\hline Level 2 & $10.083 b$ & $9.167 a$ & 13.833b & $11.583 b$ & $10.833 b$ \\
\hline Level 3 & $12.000 \mathrm{a}$ & $12.000 \mathrm{~b}$ & $10.250 c$ & 11.333b & $12.833 \mathrm{c}$ \\
\hline Level 4 & $9.000 \mathrm{~b}$ & $13.500 c$ & $10.583 \mathrm{c}$ & $7.917 \mathrm{c}$ & $11.083 \mathrm{~b}$ \\
\hline$F$-value & 34.437 & 71.262 & 62.817 & 56.595 & 40.024 \\
\hline
\end{tabular}

Different letters $(a-c)$ indicate significant differences.

bands were obtained after running the ISSR PCR products in $2 \%$ gels, and smeared or weak bands obtained with certain primers were excluded from the ISSR analysis (Zhu et al.,
2015). Reproducible bands were scored as 1 (presence) or 0 (absence) for individuals, and matrices generated by each primer sets. The binary matrix was used under Hardy-Weinberg 
TABLE 3 | Primers used for ISSR amplification.

\begin{tabular}{lllc}
\hline $\begin{array}{l}\text { Primer } \\
\text { name }\end{array}$ & Sequence $\left(\mathbf{5}^{\prime} \mathbf{3}^{\prime} \mathbf{)}\right.$ & $\begin{array}{l}\text { Primer } \\
\text { abbreviation }\end{array}$ & $\begin{array}{c}\text { Annealing } \\
\text { temperature }\left({ }^{\circ} \mathbf{C}\right)\end{array}$ \\
\hline 807 & AGAGAGAGAGAGAGAGT & (AG) $8 \mathrm{~T}$ & 50 \\
808 & AGAGAGAGAGAGAGAGC & (AG) $8 \mathrm{C}$ & 50 \\
810 & GAGAGAGAGAGAGAGAT & (GA) $8 \mathrm{~T}$ & 50 \\
811 & GAGAGAGAGAGAGAGAC & (GA) $8 \mathrm{C}$ & 50 \\
823 & TCTCTCTCTCTCTCTCC & (TC) $8 \mathrm{C}$ & 52 \\
841 & GAGAGAGAGAGAGAGAYC & (GA) $8 \mathrm{YC}^{\mathrm{a}}$ & 52 \\
842 & GAGAGAGAGAGAGAGAYG & (GA) $8 \mathrm{YG}^{\mathrm{a}}$ & 52 \\
866 & CTCCTCCTCCTCCTCCTC & (CTC) 6 & 59 \\
\hline
\end{tabular}

${ }^{a} Y=C / T$.

equilibrium to calculate the genetic similarity and distance using POPGEN1.32 (Yeh et al., 1997). The test was repeated three times.

\section{RESULTS AND DISCUSSION}

\section{Development of NIL-R in the Parthenogenetically Reproduced F. occidentalis}

A NIL of F. occidentalis, which was highly resistant to spinosad (NIL-R), was obtained by eight-round of backcrossing and spinosad screening. The resistance ratios of the F1 and $\mathrm{BC} 3$ adult females were $<8$, respectively, indicating that the resultant progeny had a low level resistance to spinosad. The resistance ratio of NIL-R, however, was $>10^{4}$, demonstrating that NIL-R retained high level of resistance comparable to its parental resistant Spin- $R$ strain (Table 4).

In comparison to the backcrossed inbred lines (BILs) used in amphigenetic insects, one major difference was that we obtained resistant males (e.g., F1P1) by parthenogenesis and insecticide screening, while in BILs, self-crossing, insecticide screening and one additional step of males selecting are used to generate resistant males (Zhu et al., 2015). The other difference was the step of $\mathrm{BC} 8$ females backcrossing with resistant males from $\mathrm{BC} 7 \mathrm{P} 1$, but not self-crossing used in amphigenetic insects. With backcrossing, we obtained the NIL-R resistant females through one hybridization (Figure 1), whereas with self-crossing in a haplo-diploid system; we will need two generations to archive the same goal. Our approach not only saves time but also produces more resistant males.

\section{Optimization of ISSR-PCR Reaction System}

The electrophoretic profile of F. occidentalis orthogonal ISSR-PCR was shown in Figure 2. According to orthogonal design-direct analysis, the best product had a score of 23, with polymorphic bands, high-definition, and clear background, and the worst product had a score of 1 (Table 1). Based on the $F$-value, the ranking of factors from the most to least effective was dNTPs $>$ primer $>$ Taq polymerase $>$ DNA $>\mathrm{Mg}^{2+}$, and the optimal concentration for each factor was $1.0 \mathrm{mmol} \cdot \mathrm{L}^{-1}$ $\mathrm{Mg}^{2+}, 0.25 \mathrm{mmol} \cdot \mathrm{L}^{-1}$ dNTPs, $2 \mu \mathrm{mol} \cdot \mathrm{L}^{-1}$ primer, $0.5 \mathrm{U}$ of Taq polymerase, and $30 \mathrm{ng}$ DNA template (Table 2, Figure 2). The ranking of factors affecting amplification results is consistent with findings in the multicolored Asian lady beetle, Harmonia axyridis Pallas (Guan et al., 2008). The optimal concentration of dNTPs is similar to $S$. furcifera and gypsy moth, Lymantria dispar Linnaeus (Chen et al., 2014; Xie et al., 2014). The optimal concentrations of primer and Taq polymerase, however, are different from $H$. axyridis, S. furcifera, and $L$. dispar, suggesting that ISSR-PCR reaction system requires optimization study for each species independently.

\section{Evaluation of Isogenicity}

The genetic similarity between Ivf03 and Spin-R was low (0.6395, Figure 3, Table S1). After one round of crosses and backcrosses, the genetic similarity between Ivf03 and $\mathrm{BC} 1$ increased to 0.8024 . The isogenicity between Ivf03 and the offspring of backcrosses increased steadily, at the final (8th) round, the genetic similarity between NIL-R and Ivf03 reached 0.9890, indicating a near identical genetic background. Based on the near-isogenicity rating estimated by ISSR marker, NIL-R strain was more similar to its susceptible parent (Ivf03) than to its original resistant parent (Spin-R) while retaining a high level of spinosad resistance (Table 4). These results indicate that the method used here is useful for constructing NILs of $F$. occidentalis.

Suneson (1954) first used the term "Near-isogenic lines" to document the effect of stem rust on the wheat production. Up to date, NILs have been used extensively in economically important crops, including corn, wheat, tomato, and cotton (Wells et al., 1986; Yang et al., 1995; Monforte and Tanksley, 2000; Zhou et al., 2005). Moreover, NILs have been adopted in entomological research to illustrate the genetic underpinnings of insecticide resistance. Fitness cost of insecticide resistance in parthenogenetic insects is direct comparison of fitness between a resistant field population and a susceptible laboratory population (Foster et al., 1997; Bielza et al., 2008). This method, however, overlooks the effect of different genetic background or genes linked to resistance loci, which potentially could have deleterious consequences (Parker, 1991; Bergelson and Purrington, 1996; Haluzik et al., 2004). Clarke and McKenzie (1987) suggested that the genetic background might include specific modifier genes, which could act to reduce fitness cost of the resistant strain. Mu et al. (2005b) have reported that when treated with lambda-cyhalothrin, the respiratory rate of the NIL-R strain was higher than its original resistant strain of the beet armyworm, although they had the same level of resistance. These results demonstrated the biological impacts caused by differences in their genetic backgrounds. Theoretically, phenotypic differences between a pair of NILs can reflect the impacts of the target genes. Therefore, the use of NILs, which differ only in their susceptibility to insecticides would be the most accurate method 
TABLE 4 | Susceptibility of Frankliniella occidentalis strains to spinosad.

\begin{tabular}{|c|c|c|c|c|c|}
\hline Strain & $n$ & Slope (SE) & $\mathrm{LC}_{50}, 95 \% \mathrm{FL}^{\mathrm{a}}(\mathrm{mg} / \mathrm{L})$ & $\chi^{2}(\mathrm{df})^{b}$ & $\mathbf{R R}^{\mathbf{c}}$ \\
\hline Ivf03 & 297 & $1.7(0.2)$ & $0.072(0.052-0.096)$ & $0.549(4)$ & 1 \\
\hline Spin-R & 223 & $2.0(0.4)$ & $2.7 \times 10^{3}\left(2.0 \times 10^{3}-4.3 \times 10^{3}\right)$ & $1.987(4)$ & $3.8 \times 10^{4}$ \\
\hline F1 & 256 & $1.7(0.3)$ & $0.46(0.35-0.66)$ & $1.905(4)$ & 6.4 \\
\hline BC3 & 204 & $1.8(0.3)$ & $0.52(0.39-0.70)$ & $0.429(4)$ & 7.2 \\
\hline NIL-R & 255 & $2.0(0.3)$ & $2.6 \times 10^{3}\left(2.0 \times 10^{3}-3.4 \times 10^{3}\right)$ & $2.176(5)$ & $3.6 \times 10^{4}$ \\
\hline
\end{tabular}

${ }^{a} F L$, fiducial limit.

${ }^{b} d f$, degrees of freedom.

${ }^{c} R R$, resistance ratio. $R R=L C_{50}$ of a strain/LC50 of IVfO3.

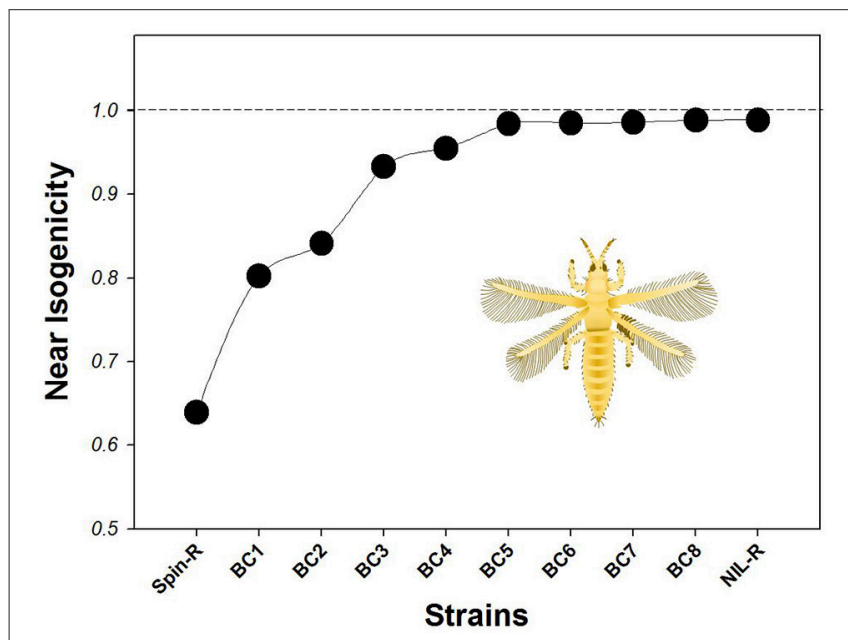

FIGURE 3 | Genetic similarity of 10 strains based on ISSR polymorphism. Each point represents the genetic similarity between the corresponding strain and Ivf03. The dash line represents identical genetic background to susceptible parental strain Ivf03.

to characterize the resistance trait, as it allows a precise estimation of the pleiotropic consequences of the resistant mutation by eliminating/mitigating the effect of genetic variance (Jiang et al., 2007; Zhu et al., 2016). Combining with the next generation sequencing (NGS) and QTL mapping, NILs can be a valuable resource to search and map genes associated with resistance at the genome level. By mining the midgut transcriptomes generated from a pair of NILs, a novel ABC transporter was found to be associated with Bt resistance in Plutella xylostella (Xie et al., 2012; Guo et al., 2015; Zhu et al., 2015, 2016). Field evolved spinosad resistance has been documented in several insect pest species (Baxter et al., 2010; Hsu et al., 2012; Puinean et al., 2013; Hou et al., 2014). The mechanistic study of spinosad resistance in F. occidentalis will be greatly facilitated by these newly established resistant and susceptible NILs.

Construction methods of NILs in plants and amphigenetic insects are basically the same because of the commonality in their bisexual production system. In parthenogenetically reproduced animals, however, these conventional strategies have failed, leaving a significant gap in the mechanistic study of resistance in these animals. Parthenogenesis occurs predominantly among insects, including Apoidea, Chalcidoidea, Coccoidea, Thripidae, Aleyroidae, and two Scolytidae-the bark and ambrosia beetles (Darlington, 1937; Whiting, 1945; Takenouchi and Takagi, 1967; White, 1977). Parthenogenesis plays an important role in the range distribution and population augmentation in some insect species. Compared with amphigenetic insects, parthenogenetic insects can occupy certain niche more effectively (Kearney, 2005). Because parthenogenesis allows insects to exploit new resources while avoiding the constraints of finding a mate, so they are able to survive in a wide range of environmental conditions, which is essential for successful colonization and invasiveness (Davis, 2009; Liebhold et al., 2016). However, Domes et al. (2007) reported that parthenogenetic oribatid soil mites had a greater fitness cost (e.g., reduced egg production) associated with the resource depletion than its sexual counterparts, suggesting that parthenogenetic species tend to have advantages over sexual ones in constant than variable environments. This, at least partially, explains why parthenogenesis is much common among agricultural pests than other non-pest species, as agricultural environments are stable and resourceabundant.

Phloem-feeding arthropods, including aphids, whiteflies, thrips, and spider mites, reproduce both asexually and sexually. By rotating these two reproductive strategies, they can breed rapidly under not only stable conditions, but also changing environments (Kanbe and Akimoto, 2009). This unique reproductive strategy, coupled with the ineffectiveness of $B t$ toxins (Raps et al., 2001; Dutton et al., 2002) and the development of insecticide resistance (Walling, 2008) make phloem-feeding arthropods one of the most challenging group of pests to control. Here we established the first NILs in a parthenogenetically reproduced thrips species. By developing this toolset, we are able to segregate individual resistance and facilitate the mechanistic study of insecticide resistances in phloem-feeding arthropods.

\section{AUTHOR CONTRIBUTIONS}

QW, GY, YW, and BH. conceived and designed the experiment; GY. performed the experiment; GY, YW, XL, and XZ. analyzed the data; BX, WX, SW, and YZ. contributed reagents/materials/analysis tools; GY. drafted the paper. QW and $\mathrm{XZ}$. edited the manuscript and supervised the entire project. 


\section{FUNDING}

This work was supported by grants from the National Science and Technology support task (2012BAD19B06), the Natural Science Foundation of China (31371965, 31572037), the Beijing Key Laboratory for Pest Control and Sustainable Cultivation of Vegetables, and the Science and Technology Innovation Program of the Chinese Academy of Agricultural Sciences (AAS-ASTIP-IVFCAAS).

\section{REFERENCES}

Baxter, S. W., Chen, M., Dawson, A., Zhao, J. Z., Vogel, H., Shelton, A. M., et al. (2010). Mis-spliced transcripts of nicotinic acetylcholine receptor $\alpha 6$ are associated with field evolved spinosad resistance in Plutella xylostella (L.). PLoS Genet. 6:e1000802. doi: 10.1371/journal.pgen.1000802

Bell, G. (1982). The Masterpiece of Nature: The Evolution and Genetics of Sexuality. Cambridge: CUP Archive

Bergelson, J., and Purrington, C. B. (1996). Surveying patterns in the cost of resistance in plants. Am. Nat. 148, 536-558. doi: 10.1086/285938

Bielza, P., Quinto, V., Contreras, J., Torné, M., Martin, A., and Espinosa, P. J. (2007b). Resistance to spinosad in the western flower thrips, Frankliniella occidentalis (Pergande), in greenhouses of south-eastern Spain. Pest Manag. Sci. 63, 682-687. doi: 0.1002/ps.1388

Bielza, P., Quinto, V., Fernandez, E., Grávalos, C., and Contreras, J. (2007a). Genetics of spinosad resistance in Frankliniella occidentalis (Thysanoptera: Thripidae). J. Econ. Entomol. 100, 916-920. doi: 10.1093/jee/100.3.916

Bielza, P., Quinto, V., Grávalos, C., Abellán, J., and Fernández, E. (2008). Lack of fitness costs of insecticide resistance in the western flower thrips (Thysanoptera: Thripidae). J. Econ. Entomol. 101, 499-503. doi: 10.1603/00220493(2008)101[499:lofcoi]2.0.co;2

Bink-Moenen, R. M., and Mound, L. A. (1990). "Whiteflies: diversity, biosystematics and evolutionary patterns," in Whiteflies: Their Bionomics, Pest Status, and Management, ed D. Gerling (Andover, MA: Intercept Ltd), 1-12.

Blanco, A., Simeone, R., and Gadaleta, A. (2006). Detection of QTLs for grain protein content in durum wheat. Theor. Appl. Genet. 112, 1195-1204. doi: 10.1007/s00122-006-0221-6

Brødsgaard, H. F. (1994). Insecticide resistance in European and African strains of western flower thrips (Thysanoptera: Thripidae) tested in a new residue-onglass test. J. Econ. Entomol. 87, 1141-1146. doi: 10.1093/jee/87.5.1141

Brouwer, D. J., and St Clair, D. A. (2004). Fine mapping of three quantitative trait loci for late blight resistance in tomato using near isogenic lines (NILs) and sub-NILs. Theor. Appl. Genet. 108, 628-638. doi: 10.1007/s00122-003-1469-8

Bryan, D. E., and Smith, R. F. (1956). The Frankliniella occidentalis (Pergande) complex in California (Thysanoptera: Thripidae). Univ. Calif. Publ. Entomol. 10, 359-410.

Chen, F., Luo, Y., Shi, J., Wu, Y., and Du, Q. (2014). Optimization and establishment of issr reaction system for gypsy moth (Lymantria dispar linnaeus). Chin. Agric. Sci. Bull. 30, 42-45. doi: 10.11924/j.issn.1000-6850.2013-2719

Clarke, G. M., and McKenzie, J. A. (1987). Developmental stability of insecticide resistant phenotypes in blowfly; a result of canalizing natural selection. Nature 325, 345-346. doi: 10.1038/325345a0

Darlington, C. D. (1937). Recent Advances in Cytology, 2nd Edn. London: J And A Churchill.

Davis, M. A. (2009). Invasion Biology. Oxford: Oxford University Press.

Dixon, A. F. G. (1987). "Parthenogenetic reproduction and the rate of increase in aphids," in Aphids: Their Biology, Natural Enemies, and Control, Vol. 2A. eds A. K. Minks and P. Harrewijn (Amsterdam: Elsevier), 269-287.

Domes, K., Scheu, S., and Maraun, M. (2007). Resources and sex: soil recolonization by sexual and parthenogenetic oribatid mites. Pedobiologia 51, 1-11. doi: 10.1016/j.pedobi.2006.11.001

\section{ACKNOWLEDGMENTS}

We thank Dr. Zhu Xun for his suggestions on the experimental design.

\section{SUPPLEMENTARY MATERIAL}

The Supplementary Material for this article can be found online at: http://journal.frontiersin.org/article/10.3389/fphys. 2017.00130/full\#supplementary-material

Dutton, A., Klein, H., Romeis, J., and Bigler, F. (2002). Uptake of Bttoxin by herbivores feeding on transgenic maize and consequences for the predator Chrysoperla carnea. Ecol. Entomol. 27, 441-447. doi: 10.1046/j.1365-2311.2002.00436.x

Edwards, K. D., Lynn, J. R., Gyula, P., Nagy, F., and Millar, A. J. (2005) Natural allelic variation in the temperature-compensation mechanisms of the Arabidopsis thaliana circadian clock. Genetics 170, 387-400. doi: 10.1534/genetics.104.035238

Foster, S. P., Harrington, R., Devonshire, A. L., Denholm, I., Clark, S. J., and Mugglestone, M. A. (1997). Evidence for a possible fitness trade-off between insecticide resistance and the low temperature movement that is essential for survival of UK populations of Myzus persicae (Hemiptera: Aphididae). Bull. Entomol. Res. 87, 573-579. doi: 10.1017/s0007485300038669

Godwin, I. D., Aitken, E. A., and Smith, L. W. (1997). Application of inter simple sequence repeat (ISSR) markers to plant genetics. Electrophoresis 18, 1524-1528. doi: 10.1002/elps.1150180906

Guan, H., Chi, D., Zheng, Y., Yu, J., and Li, X. (2008). Optimization for ISSR-PCR reaction system of Harmonia axyridis using orthogonal design. J. Northeast For. Univ. 36, 46-48. doi: 10.13759/j.cnki.dlxb.2008.12.022

Guo, Z., Kang, S., Zhu, X., Xia, J., Wu, Q., Wang, S., et al. (2015). Down-regulation of a novel $\mathrm{ABC}$ transporter gene (Pxwhite) is associated with Cryl Ac resistance in the diamondback moth, Plutella xylostella (L.). Insect Biochem. Mol. Biol. 59, 30-40. doi: 10.1016/j.ibmb.2015.01.009

Haluzik, M., Colombo, C., Gavrilova, O., Chua, S., Wolf, N., Chen, M., et al. (2004). Genetic background (C57BL/6J versus FVB/N) strongly influences the severity of diabetes and insulin resistance in ob/ob mice. Endocrinology 145, 3258-3264. doi: 10.1210/en.2004-0219

Hardstone, M. C., Komagata, O., Kasai, S., Tomita, T., and Scott, J. G. (2010). Use of isogenic strains indicates CYP9M10 is linked to permethrin resistance in Culex pipiens quinquefasciatus. Insect Mol. Biol. 19, 717-726. doi: 10.1111/j.1365-2583.2010.01030.x

Helle, W., and Bolland, H. R. (1967). Karyotypes and sex-determination in spider mites (Tetranychidae). Genetica 38, 43-53. doi: 10.1007/bf015 07446

Herron, G. A., and James, T. M. (2007). Insecticide resistance in Australian populations of Western Flower Thrips, Frankliniella occidentalis (Pergande) (Thysanoptcra: Thripidae). Gen. Appl. Entomol. 36, 1.

Hou, W. J., Li, F., Wu, Q. J., Xu, B. Y., and Zhang, Y. J. (2013). Biochemical mechanism of resistance to spinosad in Frankliniella occidentalis. Chin. J. Appl. Entomol. 50, 1042-1048. doi: 10.7679/j.issn. 2095-1353.2013.144

Hou, W., Liu, Q., Tian, L., Wu, Q., Zhang, Y., Xie, W., et al. (2014). The $\alpha 6$ nicotinic acetylcholine receptor subunit of Frankliniella occidentalis is not involved in resistance to spinosad. Pestic. Biochem. Phys. 111, 60-67. doi: 10.1016/j.pestbp.2014.03.004

Hsu, J. C., Feng, H. T., Wu, W. J., Geib, S. M., Mao, C. H., and Vontas, J. (2012). Truncated transcripts of nicotinic acetylcholine subunit gene Bd $\alpha 6$ are associated with spinosad resistance in Bactrocera dorsalis. Insect Biochem. Mol. Biol. 42, 806-815. doi: 10.1016/j.ibmb.2012.07.010

Immaraju, J. A., Paine, T. D., Bethke, J. A., Robb, K. L., and Newman, J. P. (1992). Western flower thrips (Thysanoptera: Thripidae) resistance to insecticides in coastal California greenhouses. J. Econ. Entomol. 85, 9-14. doi: $10.1093 /$ jee/85.1.9 
Jiang, X. F., Luo, L. Z., and Zhang, L. (2007). Relative fitness of near isogenic lines for melanic and typical forms of the oriental armyworm, Mythimna separata (Walker). Environ. Entomol. 36, 1296-1301. doi: 10.1093/ee/36.5.1296

Kanbe, T., and Akimoto, S. (2009). Allelic and genotypic diversity in long-term asexual populations of the pea aphid, Acyrthosiphon pisum in comparison with sexual populations. Mol. Ecol. 18, 801-816. doi: 10.1111/j.1365-294x.2008.04077.x

Kearney, M. (2005). Hybridization, glaciation and geographical parthenogenesis. Trends Ecol. Evol. 20, 495-502. doi: 10.1016/j.tree.2005.06.005

Liebhold, A. M., Berec, L., Brockerhoff, E. G., Epanchin-Niell, R. S., Hastings, A., Herms, D. A., et al. (2016). Eradication of invading insect populations: from concepts to applications. Annu. Rev. Entomol. 61, 335-352. doi: 10.1146/annurev-ento-010715-023809

Loudet, O., Gaudon, V., Trubuil, A., and Daniel-Vedele, F. (2005). Quantitative trait loci controlling root growth and architecture in Arabidopsis thaliana confirmed by heterogeneous inbred family. Theor. Appl. Genet. 110, 742-753. doi: 10.1007/s00122-004-1900-9

Loughner, R. L., Warnock, D. F., and Cloyd, R. A. (2005). Resistance of greenhouse, laboratory, and native populations of western flower thrips to spinosad. HortScience 40, 146-149.

Martin, N. A., Workman, P. J., and Popay, A. J. (1994). "Confirmation of a pesticide-resistant strain of western flower thrips in New Zealand," in Paper Presented at the Proceedings of the Forty Seventh New Zealand Plant Protection Conference (Waitangi).

Matsuura, K. (2010). "Sexual and asexual reproduction in termites," in Biology of Termites: A Modern Synthesis, eds D. E. Bignell, Y. Roisin, and N. Lo (Berlin: Springer Netherlands), 255-277.

Monforte, A. J., and Tanksley, S. D. (2000). Development of a set of near isogenic and backcross recombinant inbred lines containing most of the Lycopersicon hirsutum genome in a $L$. esculentum genetic background: a tool for gene mapping and gene discovery. Genome 43, 803-813. doi: 10.1139/gen-43-5-803

Mu, W., Liu, F., and Wu, K. (2005a). RAPD marker of near isogence lines of Spodoptera exigua (hübmer) (lepidoptera:noctuidae) resistant to lambda -cyhalothrin. Biotechnology 15, 17-19. doi: 10.3969/j.issn.1004-311X.2005.03.007

Mu, W., Wu, K., Guo, Y., and Zhang, W. (2005b). Comparison of the respiratory rate among different resistant strains of the beet armyworm, Spodoptera exigua (Hubner) (Lepidoptera: Noctuidae) to lambda-cyhalothrin. Acta Entomol. Sin. 48, 881. doi: 10.3321/j.issn:0454-6296.2005.06.011

$\mathrm{Mu}, \mathrm{W}$., Wu, K., and Zhang, W. (2004). Establishment of the near isogenic line strain esistant to lambda-cyhalothrin in Spodoptera exigua (Huebner) (Lepidoptera: Notuidae). Acta Entomol. Sin. 47, 591-594. doi: $10.16380 / j . k c x b .2004 .05 .008$

Muehlbauer, G. J., Specht, J. E., Thomas-Compton, M. A., Staswick, P. E., and Bernard, R. L. (1988). Near-isogenic lines-a potential resource in the integration of conventional and molecular marker linkage maps. Crop Sci. 28, 729-735. doi: $10.2135 /$ cropsci1988.0011183x002800050002x

Murai, T. (1990). "Parthenogenetic reproduction in Thrips tabaci and Frankliniella intonsa," in Advances in Invertebrate Reproduction 5, eds W. Engels, H. H. Kaatz, A. Zilikens, Z. L. P. Simões, A. Truve, R. Braun, and F. Dittrich (Amsterdam: Elsevier Science), 357-362.

Parker, M. A. (1991). Nonadaptive evolution of disease resistance in an annual legume. Evolution 45, 1209-1217. doi: 10.2307/2409728

Pierce, D. A., and Lucchesi, J. C. (1981). Analysis of a dispersed repetitive DNA sequence in isogenic lines of Drosophila. Chromosoma 82, 471-492. doi: 10.1007/bf00295007

Puinean, A. M., Lansdell, S. J., Collins, T., Bielza, P., and Millar, N. S. (2013). A nicotinic acetylcholine receptor transmembrane point mutation (G275E) associated with resistance to spinosad in Frankliniella occidentalis. J. Neurochem. 124, 590-601. doi: 10.1111/jnc.12029

Raps, A., Kehr, J., Gugerli, P., Moar, W. J., Bigler, F., and Hilbeck, A. (2001). Immunological analysis of phloem sap of Bacillus thuringiensis corn and of the nontarget herbivore Rhopalosiphum padi (Homoptera: Aphididae) for the presence of CrylAb. Mol. Ecol. 10, 525-533. doi: 10.1046/j.1365-294x.2001.01236.x

Robb, K. L., Newman, J., Virzi, J. K., and Parrella, M. P. (1995). "Insecticide resistance in western flower thrips," in Thrips Biology and Management, eds L. P. Bruce, S. Margaret, and L. Trevor (New York, NY: Springer US), 341-346.
Roush, R. T., and Wolfenbarger, D. A. (1985). Inheritance of methomyl resistance in the tobacco budworm (Lepidoptera: Noctuidae). J. Econ. Entomol. 78, 1020-1022. doi: 10.1093/jee/78.5.1020

Sakimura, K. (1962). Frankliniella occidentalis (Thysanoptera: Thripidae), a vector of the tomato spotted wilt virus, with special reference to the color forms. Ann. Entomol. Soc. Am. 55, 387-389. doi: 10.1093/aesa/55.4.387

Shen, L., Courtois, B., McNally, K. L., Robin, S., and Li, Z. (2001). Evaluation of near-isogenic lines of rice introgressed with QTLs for root depth through marker-aided selection. Theor. Appl. Genet. 103, 75-83. doi: $10.1007 / \mathrm{s} 001220100538$

LeOra Software (1997). POLO-PC: Probit and Logit Analysis. Berkeley, CA.

St Leger, R., Joshi, L., Bidochka, M. J., and Roberts, D. W. (1996). Construction of an improved mycoinsecticide overexpressing a toxic protease. Proc. Natl. Acad. Sci. U.S.A. 93, 6349-6354. doi: 10.1073/pnas.93.13.6349

Suneson, C. A. (1954). Effect of stem rust on the yield of wheat. Agron. J. 46, $112-114$.

Takenouchi, Y., and Takagi, K. (1967). A chromosome study of two parthenogenetic scolytid beetles. Annot. Zool. Jpn. 40, 105-110.

Thompson, G. D., Dutton, R., and Sparks, T. C. (2000). Spinosad-a case study: an example from a natural products discovery programme. Pest Manag. Sci. 56, 696-702. doi: 10.1002/1526-4998(200008)56:8<696::aid-ps182>3.0.co;2-5

Tucker, K. W. (1958). Automictic parthenogenesis in the honey bee. Genetics 43, 299.

von-Korff, M., Wang, H., Léon, J., and Pillen, K. (2004). Development of candidate introgression lines using an exotic barley accession (Hordeum vulgare ssp. spontaneum) as donor. Theor. Appl. Genet. 109, 1736-1745. doi: $10.1007 / \mathrm{s} 00122-004-1818-2$

Walling, L. L. (2008). Avoiding effective defenses: strategies employed by phloem-feeding insects. Plant Physiol. 146, 859-866. doi: 10.1104/pp.107.1 13142

Wan, Y. R., He, B. Q., Yuan, G. D., Wei, G. S., and Wu, Q. J. (2016). Development of resistance to spinosyns in populations of western flower thrips in Beijing and Yunnan. Chin. J. Appl. Entomol. 2, 396-402. doi: 10.7679/j.issn.2095-1353.2016.052

Wang, X. G., Ji, Z. J., Jing, C. A. I., Li, X. M., and, Yang, C. D. (2009). Construction of near isogenic lines for pericarp color and evaluation on their near isogenicity in rice. Rice Sci. 16, 261-266. doi: 10.1016/S1672-6308(08)60089-X

Wells, R., Meredith, W. R., and Williford, J. R. (1986). Canopy photosynthesis and its relationship to plant productivity in near-isogenic cotton lines differing in leaf morphology. Plant Physiol. 82, 635-640. doi: 10.1104/pp.82.3.635

White, M. J. D. (1977). Animal Cytology and Evolution. Cambridge: Cambridge University Press.

White, N. D. G., and Bell, R. J. (1988). Inheritance of malathion resistance in a strain of Tribolium castaneum (Coleoptera: Tenebrionidae) and effects of resistance genotypes on fecundity and larval survival in malathion-treated wheat. J. Econ. Entomol. 81, 381-386. doi: 10.1093/jee/81.1.381

Whiting, P. W. (1945). The evolution of male haploidy. Q. Rev. Biol. 20, 231-260. doi: $10.1086 / 394884$

Williams, T., Valle, J., and Viñuela, E. (2003). Is the naturally derived insecticide Spinosad ${ }^{\circledR}$ compatible with insect natural enemies? Biocontrol Sci. Technol. 13, 459-475. doi: 10.1080/0958315031000140956

Xie, J., Guo, J., and Jin, D. (2014). Establishment and optimization of ISSR-PCR reaction system with orthogonal design for Sogatella furcifera. Plant Protect. 40, 109-112. doi: 10.3969/j.issn.0529-1542.2014.02.021

Xie, W., Lei, Y., Fu, W., Yang, Z., Zhu, X., Guo, Z., et al. (2012). Tissue-specific transcriptome profiling of Plutella xylostella third instar larval midgut. Int. J. Biol. Sci. 8, 1142-1155. doi: 10.7150/ijbs.4588

Yang, W. J., Nadolska-Orczyk, A., Wood, K. V., Hahn, D. T., Rich, P. J., Wood, A. J., et al. (1995). Near-isogenic lines of maize differing for glycinebetaine. Plant Physiol. 107, 621-630. doi: 10.1104/pp.107.2.621

Yeh, F. C., Yang, R. C., Boyle, T. B., Ye, Z. H., and Mao, J. X. (1997). POPGENE, the User-Friendly Shareware for Population Genetic Analysis. Molecular Biology and biotechNology Centre. Edmonton, AB: University of Alberta.

Young, N. D., Zamir, D., Ganal, M. W., and Tanksley, S. D. (1988). Use of isogenic lines and simultaneous probing to identify DNA markers tightly linked to the tm-2a gene in tomato. Genetics 120, 579-585.

Yuan, Z., Yangchun, W., and Jian, Z. (2010). The Construction of heatresistant near isogenic line (NIL) of Bombyx mori and the development 
of molecular marker breeding technique. Agric. Sci. Technol. 11, 92-95. doi: 10.16175/j.cnki.1009-4229.2010.01.049

Zhang, Z. J., Wu, Q. J., Li, X. F., Zhang, Y. J., Xu, B. Y., and Zhu, G. R. (2007). Life history of western flower thrips, Frankliniella occidentalis (Thysanoptera, Thripae), on five different vegetable leaves. J. Appl. Entomol. 131, 347-354. doi: 10.1111/j.1439-0418.2007.01186.x

Zhao, G., Liu, W., Brown, J. M., and Knowles, C. O. (1995). Insecticide resistance in field and laboratory strains of western flower thrips (Thysanoptera: Thripidae). J. Econ. Entomol. 88, 1164-1170. doi: 10.1093/jee/88.5.1164

Zhou, R., Zhu, Z., Kong, X., Huo, N., Tian, Q., Li, P., et al. (2005). Development of wheat near-isogenic lines for powdery mildew resistance. Theor. Appl. Genet. 110, 640-648. doi: 10.1007/s00122-004-1889-0

Zhu, X., Lei, Y., Yang, Y., Baxter, S. W., Li, J., Wu, Q., et al. (2015). Construction and characterization of near-isogenic Plutella xylostella (Lepidoptera: Plutellidae) strains resistant to Cry1Ac toxin. Pest Manag. Sci. 71, 225-233. doi: $10.1002 /$ ps.3785
Zhu, X., Yang, Y., Wu, Q., Wang, S., Xie, W., Guo, Z., et al. (2016). Lack of fitness costs and inheritance of resistance to Bacillus thuringiensis CrylAc toxin in a near-isogenic strain of Plutella xylostella (Lepidoptera: Plutellidae). Pest Manag. Sci. 72, 289-297. doi: 10.1002/ps.3991

Conflict of Interest Statement: The authors declare that the research was conducted in the absence of any commercial or financial relationships that could be construed as a potential conflict of interest.

Copyright $\odot 2017$ Yuan, Wan, Li, He, Zhang, Xu, Wang, Xie, Zhou and Wu. This is an open-access article distributed under the terms of the Creative Commons Attribution License (CC BY). The use, distribution or reproduction in other forums is permitted, provided the original author(s) or licensor are credited and that the original publication in this journal is cited, in accordance with accepted academic practice. No use, distribution or reproduction is permitted which does not comply with these terms. 